\title{
Air Quality Management in Tehran Using a Multi-Dimensional Decision Support System
}

\author{
Mehran Ghodousi ${ }^{1}$, Farideh Atabi ${ }^{2 *}$, Jafar Nouri $^{3}$, Alireza Gharagozlou ${ }^{4}$ \\ ${ }^{1}$ Department of Environmental Management, Graduate School of the Environment and Energy, \\ Science and Research Branch, Islamic Azad University, Tehran, Iran \\ ${ }^{2}$ Department of Environmental Engineering, Graduate School of the Environment and Energy, \\ Science and Research Branch, Islamic Azad University, Tehran, Iran \\ ${ }^{3}$ Department of Environmental Health Engineering, Tehran University of Medical Sciences, Tehran, Iran \\ ${ }^{4}$ Geomatics College, NCC of Iran, Tehran, Iran
}

Received: 7 May 2016

Accepted: 8 September 2016

\begin{abstract}
Management of air pollution in Tehran, Iran, has been a significant challenge for urban authorities in recent years owing to the number and complexity of the factors affecting the formation and spread of the pollutions. The present study used an integrated modeling approach involving Spatio, Temporal, Uncertainty Decision Support Systems (STUDSS) using Multi Criteria Decision Analysis (MCDA) and an Artificial Neural Network (ANN) for the virtual simulation and strategy assessment of air pollution. Since sources of air pollution and associated pollution control strategies are dependent on location, time and uncertain variables, Multi-Dimensional Decision Support System (MDDSS) can be efficient tool for urban air quality decision-making process. In order to model and evaluate air pollution, time-series data over a period of four years, screened and classified management strategies as well as other structural and environmental data such as land uses, terrain topography, heights of buildings, climatic conditions, population density and pollution sources were modeled using advanced software packages of MCDA and ANN. They were ultimately simulated and evaluated using the MDDSS. The results obtained from the implementation of the STUDSS showed that this tool could be used to provide sustainable solutions to air quality in metropolises and could respond to social satisfaction and economic development.
\end{abstract}

Keywords: decision support system, air quality management, robust strategy, pollution predicting

\section{Introduction}

The metropolis of Tehran currently houses more than $15 \%$ of the permanent and floating working population

*e-mail: far-atabi@jamejam.net of the country, thus exacerbating the problem of imploding centralization caused by the unique prevailing administrative, educational, and commercial structures of the region [1]. The phenomenon of urbanization has been transforming the natural landscape and habitat of Tehran for years, changing its human activity and lifestyle and causing various types of damage to its natural resources 
at local and regional levels, including breathable air and climate change [2-3].

The various sources of air pollution available in the region have created countless complex and multidimensional problems; identifying their complex structures and assessing their irreversible effects require tools that can measure the entire spatio-temporal and uncertainty dimensions in one stroke [4]. An effective air pollution management program should integrate all the required practical strategies in a way that their positive synergies create robust solutions for a fair and sustainable mitigation of air pollution across the metropolis [5].

A sustainable strategic planning requires MDDSS, a variety of expert systems, machine learning processes, and virtual simulation systems to help accurately predict the air quality under different conditions at determined times and locations [6-7]. Data analysis is used for analyzing, clustering, classifying, predicting, and creating time series patterns and can be used according to various specialized and technical methods such as statistical methods, ANN models, decision-tree analysis, genetic algorithms, and fuzzy logic theories [8-9]. MCDA techniques have demonstrated their capabilities in situations where the best decision has to be made from a multitude of criteria according to a set of objectives and pre-existing conditions and when the selected criteria also require weighing and rating in terms of their importance in meeting the goals and conditions that match those of the decision [10].

Monitoring emission inventory layers using multidimensional layers of data causes the patterns of pollution development and distribution to be identified under intended spatial and temporal conditions [11]. The use of multidimensional simulations or MDDSS in the management of air quality leads to a better understanding of the spatio-temporal variables and uncertainty conditions that affect air pollution in each of the urban macro zones [12]. MDDSS provides assessors with the opportunity to identify the main causes of the propagation of air pollution based on the analytical reports extracted from recorded time series and to also predict the likely patterns of the spread of pollution under similar spatio-temporal conditions [13]. Overall, the success and efficacy of the selected strategies can be evaluated according to MDDSS simulation results; in a way, the success and capabilities of each selected strategy can be assessed virtually and in the form of decision support models so as to determine the share of each strategy in mitigating the recorded pollution in each macro zone based on the capabilities of the chosen strategic plan and the prevailing conditions of the macro zone [14-15].

Therefore, in this study the integration of spatial, temporal, and uncertainty decision support systems with MCDA and ANN matrices was carried out for the purpose of the visual simulation of predicted air pollution before implementing the control strategies and for the final results to be determined for the macro zones' air quality after the execution of the selected plans. The prioritized strategies and their proposed weights were defined depending on the existing pollutants detected and the main requirements and opportunities for all Tehran Air Quality Zones (TAQZs). However, based on searches for various studies there is not any similar research for urban air quality management simulating past, current, and future situations of air pollution before and after execution of controlling strategies by spatio-temporal and uncertainty decision support systems.

\section{Materials and Methods}

STUDSS enables the identification of the least and most efficient requirements for sustaining air quality in every macro zone and is based specifically on detecting its structural complexity and activity impacts. All the implemented steps can be summarized in five sections. First, studying management programs for air pollution mitigation in similar metropolises, developing questionnaires to determine priorities and calculate air pollution mitigation coefficients for each screened mitigating pollution strategy with the help of experts, and ultimately calculating weights of each program accurately based on the criteria and objectives determined using the advanced technique (MCDA). Second, multi-dimensional spatial gridding and zoning of Tehran based on defined rules and functions at micro and macro scales, for which a total of 26 zones were finally defined in Tehran based on dominant conditions and typologies in each zone. Third, developing 48-monthtime-series maps as time-series air pollution models for investigating recurring patterns of the formation and development of air pollution in all zones of Tehran over a period of four years. Fourth, implementing tripartite forecasting scenarios (optimistic, pessimistic, and ordinary scenarios) to model the results obtained from involving the controlling strategies in each of the above three cases using the function defined and forecasting algorithms of ANN software. Fifth, illustrating the results obtained from implementing the management programs for air pollution mitigation using customized analyzer and predictor software as a multi-dimensional decision support system for each zone and evaluating the selected scenarios in different conditions.

\section{Creating Tehran Air Quality Zones}

Total suspended particulates (TSPs) were identified as the main problem for air quality in Tehran and were selected as an air quality indicator for the simulation and modeling of spatial cellular grid layers (SCGLs) inventory in each defined macro zone. Tehran settlements were divided into specific macro zones depending on their emission conditions, dominant typologies, related urban features, structures, infrastructures and activities, land use, and demographic characteristics as per TAQZs (Fig. 1). The location of air quality control stations and the other data required for the development of spatial data infrastructures are identified on SCGLs as the reference location. 


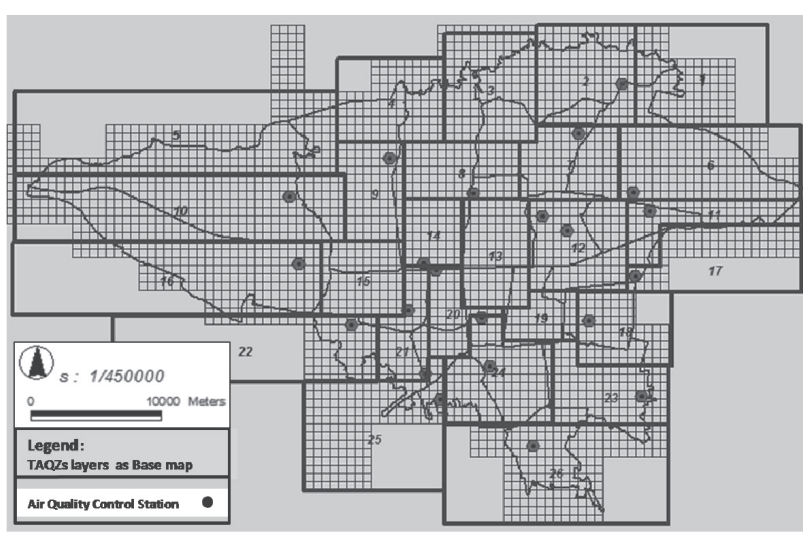

Fig. 1. Tehran Air Quality Zones (TAQZs) defined and air quality control stations distribution.

\section{Decision Tree for Air Quality Controlling Strategies}

The value definition for the classification of the weight of the strategies was first carried out by expert comments using the virtual Delphi method and then by a pairwise comparison in the MCDA; all the defined scores were categorized technically and attached to their related cellular grid layers. A virtual ad-hoc committee was held for weighing the selected strategies as the most vital part of the decision-making process using online Delphi questionnaires, which collected the experts' opinions through the customized website and held virtual training and cluster classifications. The final decision tree of the selected pollution control strategies and the priorityranking for the selected strategies using the MCDA approach has been shown in Fig. 2.

The experts' opinions were gathered through the designed questionnaires in three sections, including a general section (72 questions), an expert section (24 questions), and final section (14 questions). After categorizing the most similar responses, the initial values of the priorities and weights were determined. The final clusters of strategies were defined as the main TAQZs for air quality control programs for making a decision tree and evaluating the priorities and scores using the Delphi method and MCDA. All the scores calculated for the strategies were attached directly to their corresponding SCGL models. The final spatial MCDA analysis results specified the 14 rated strategies as: PSP (point source pollution control programs), LSP (line source pollution control programs), LR (laws and rules), ASP (area sources pollution prevention programs), LUTA (land use renovating and transportation system revised for access to sites of attraction programs), DD (demographic data for preparing and developing air-friendly programs), USS (urban spaces and structures for air-friendly planning and design), BP (behavioral pattern policies), UTMP (urban transportation and movement pattern planning), UCT (urban corridor and useful topographical spaces planning and design), UGOS (urban green areas and open spaces planning and design), TV (technology and virtual electronic services development and planning), UDCP (urban designs and comprehensive plans revised by implementing clean air-friendly policies in

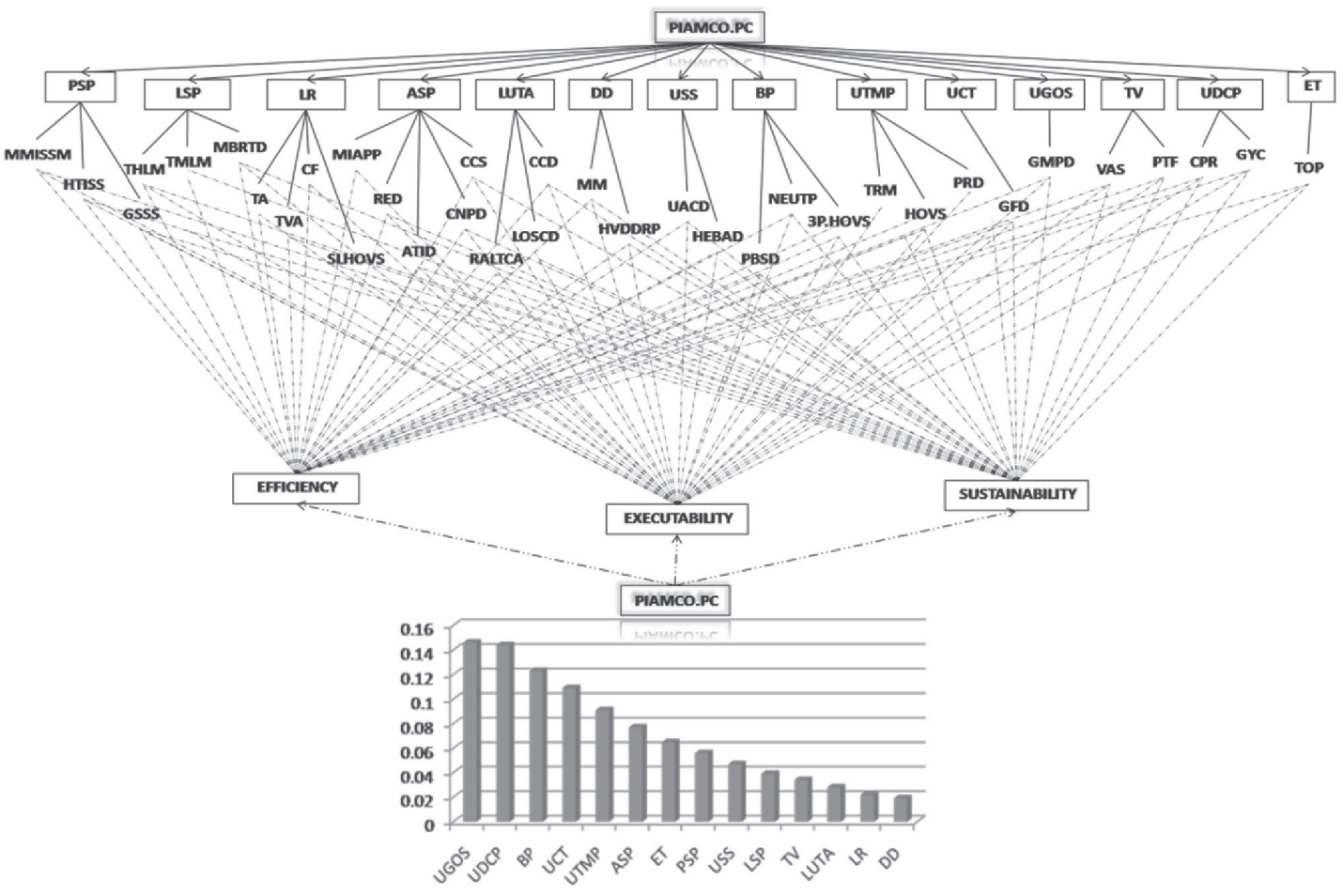

Fig. 2. The final decision tree of the selected pollution control strategies and the priority-ranking for the selected strategies using the MCDA approach. 
urban areas), ET (economical and technological policy development).

\section{Time Series Simulations for Predicting Air Pollution}

The spatial simulation of 48 monthly time series layers of air pollution in TAQZs (2011-14) demonstrates an iterative process with similar repeated operations of air pollution development and expands the spatial and temporal conditions for the similar macro zones. This process helped in predicting the simulations using ANN tools based on periodic pollution patterns and in detecting the main sources of pollution and their related factors, thereby helping determine the most suitable strategies for mitigating their impacts. The spatial visualization of the air pollution distributed across four years was simulated by separate 12-month SCGLs based on the average air quality index reports of each local station, and the expected rates of air pollution (ERAP) models were ultimately defined for each TAQZ (Fig. 3).

\section{Uncertainty Modeling by ANN Scenario-Based Simulations}

Spatiotemporal factors are often included as the core of decision-making in common decision support models. Given the complexity of the formation and management of urban air pollution, uncertainty variables were used in this paper along with spatiotemporal indicators as multiple planned scenarios to evaluate the current status and also predict and analyze the results obtained from the implementation of air pollution mitigation strategies. Under normal conditions (known as UFO - uncertainty functions by ordinary scoring), all related factors are under normal conditions, under which the strategies suiting each
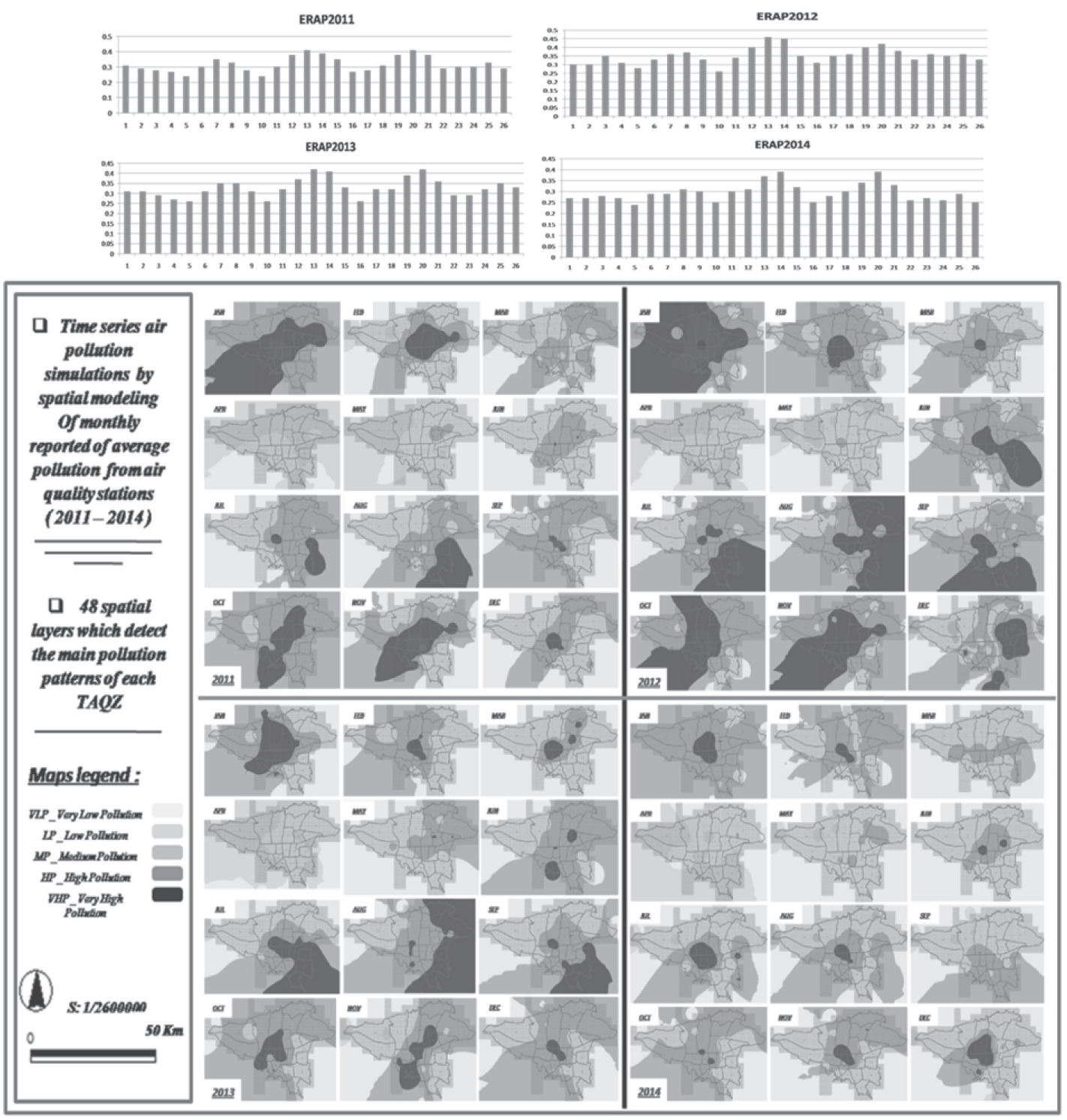

Fig. 3. Monthly time-series simulations for air pollution in Tehran from 2011 to 2014 and their related comparison charts for air pollution density patterns in 26 defined zones. 
macro zone enhance the positive aspects of the related factors and mitigate the negative conditions detected for each TAQZ. STUDSS also simulated two other uncertainty scenarios of UFMA (uncertainty functions by maximum scoring for the worst possible conditions) and UFMI (uncertainty functions by minimum scoring for the most optimistic forecast and positive conditions). For rating the strategies and situation modeling in UFMA, the highest values were taken based on a lack of selffiltration in the macro zones and while expecting the worst possible situation with the highest degree of emission for most of the specific TAQZ. The maximum number of synergic strategies for compensating for pollution was defined effectively using the most pessimistic approach. In UFMI, all the defined scores were as low as possible, given the highly positive conditions at the macro zones and the lower emission of pollutants based on time series evaluations, the environment evaluation matrices, and the best urban conditions predicted. In the UFO predicting model, all the selected urban features and defined factors simulated the normal conditions measured spatially by evaluating time series layers and other alternatives of ERAP models for all TAQZ. For measuring scores of ERAP in each macro zone and for predicting the final values for the expected rates of air pollution mitigation (ERAPM), the expected pollution level is calculated in the ANN model based on the expressed values as the following functions:
ERAP $=\sum_{i}{ }^{\mathrm{N}}[\mathrm{K}($ plla $)+\mathrm{V}($ haape $)]$

ERAPM $=\sum_{\mathrm{i}}^{\mathrm{N}}\left[\left(\mathrm{W}_{\mathrm{i}}^{\mathrm{N}}\right) *(\mathrm{PSP}, \mathrm{LSP}, \mathrm{LR}, \mathrm{ASP}\right.$, LUTA, DD, USS, BP, UTMP, UCT, UGOS, $\mathrm{TV}, \mathrm{UDCP}, \mathrm{ET})]+\sum_{\mathrm{i}}^{\mathrm{N}}[\mathrm{K}($ plla $)+\mathrm{V}($ haape $)]$

Firstly, the constant factors that be estimated by:

$$
\mathbf{K p l l a}=\mathbf{K}\left[\left(\sum_{\mathrm{i}}^{\mathrm{N}} \underline{\mathbf{P}} \mathrm{spd}\right)+\left(\sum_{\mathrm{i}}^{\mathrm{N}} \underline{\mathbf{L}} \mathrm{spd}\right)+\left(\sum_{\mathrm{i}}^{\mathrm{N}} \underline{\mathbf{L A}} \mathbf{i r}\right)\right]
$$

...where PSPD: point source pollution density factors, LSPD: linear source pollution density factors, and LAIR: land use impact classification rates. In order to obtain the variable values, the ANN model calculates the expected level of pollution according to the following function:

$$
\begin{gathered}
\text { Vhaape }=\mathbf{V}\left[\left(\sum_{\mathrm{i}}^{\mathrm{N}} \underline{\mathbf{H}} \mathrm{idr}\right)+\left(\sum_{\mathrm{i}}^{\mathrm{N}} \underline{\mathbf{A}} \mathrm{sdr}\right)+\right. \\
\left.\left(\sum_{\mathrm{i}}^{\mathrm{N}} \underline{\mathbf{A}} \mathbf{i d r}\right)+\left(\sum_{\mathrm{i}}^{\mathrm{N}} \underline{\mathbf{P}} \mathrm{dr}\right)+\left(\sum_{\mathrm{i}}^{\mathrm{N}} \underline{\mathbf{E}} \mathbf{i i}\right)\right]
\end{gathered}
$$

...where HIDR (heat islands density classification rate) simulates the distribution of hazardous thermal patches with harmful effects on public health, ASDR (accepted clean air urban spaces density rate) represents specific weights for anti-thermal urban spaces such as open green spaces, AIDR (accepted air-friendly urban infrastructures classification density rates), PDR (population density

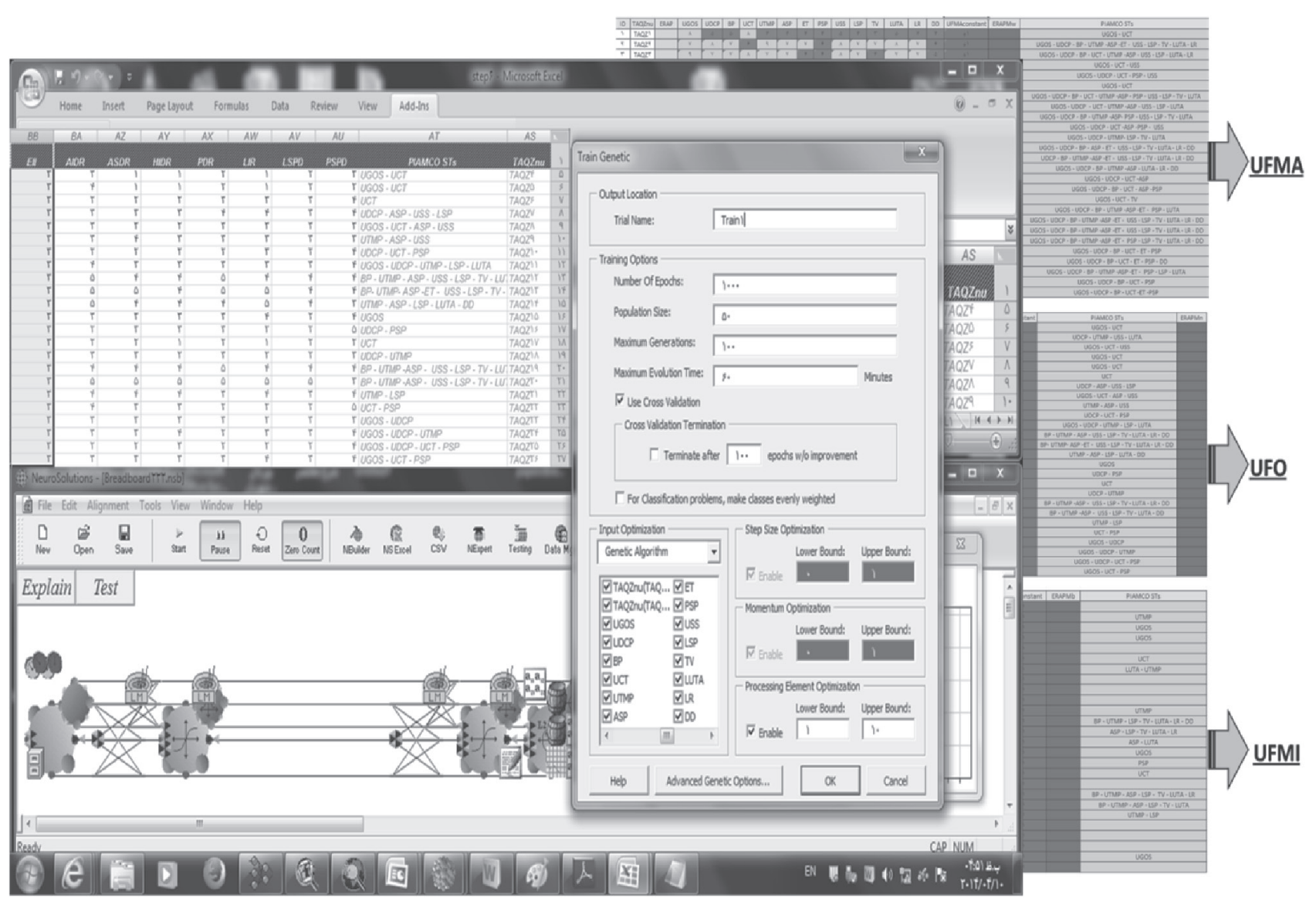

Fig. 4. Artificial neural network analyses for "ERAP" and "ERAPM" predicting simulations using tripartite forecasting scenarios. 
rate) measures the rates of population density and the impact of public activities on air quality, and EII (environmental impact index simulation) demonstrates the role of environmental factors such as climate, rain, wind, topography, and other environmental alternatives that contribute to the increase or reduction of pollution.

These factors were used for predicting the scenarios. For the UFMA scenario, the maximum weights were considered as the maximum controlling factors required by the Vhaape alternatives (Eq. 4); for the UFMI scenario, the minimum weights were defined and spatially attached to the spatial cellular grid layers and used in overlaying the modeling procedures; and for simulating the UFO scenario, the average mode and mean values of the measured scores were used in the Vhaape database, which simulated the scenario using both the ANN software and STUDSS virtual environments (Fig. 4). Time series modeling was used for predicting the ERAP values at the UFO situations; however, for the ERAP quantities at the UFMI and UFMA scenarios, other variables such as the Vhaape alternatives were simulated. Moreover, for predicting ERAPM using tripartite forecasting scenarios, other parameters such as
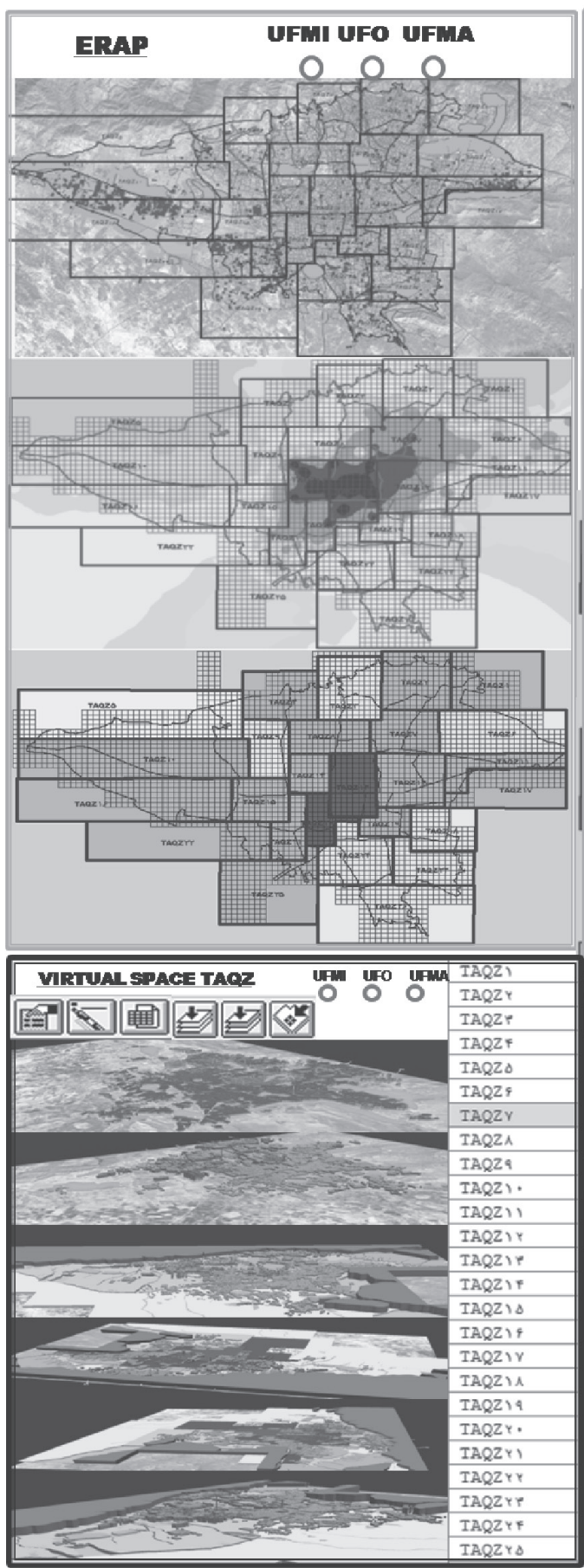

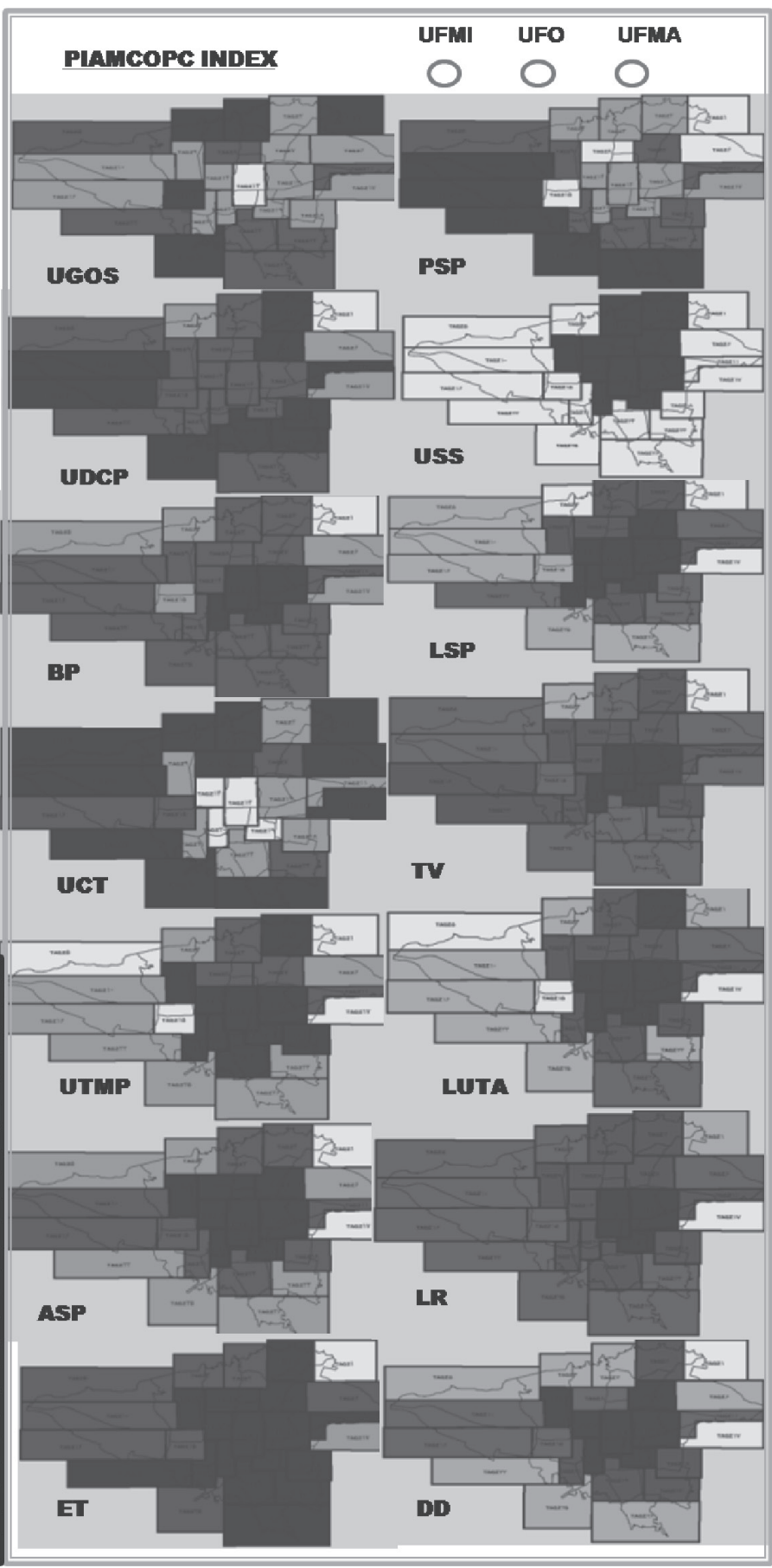

Fig. 5. MDDSS software customized by the integrated MCDA-ANN matrices and the spatio-temporal-uncertainty virtual simulations for air quality management. 
the Kplla and the scores given to the strategies were used specifically for each defined macro zone (Eq. 3). Time series data plus Kplla and Vhaape alternatives were used for the ERAP predicting models (Eq. 1) and, through integrating the control weights given to the strategies with the calculated ERAP values, the amounts of ERAPM (Eq. 2) was simulated spatially using the macro zones' cellular grid layers.

\section{Results and Discussion}

\section{Simulating TAQZs Using SCGL Models}

The main element of air pollution modeling is analysis of the trends of the past and forecasted changes that support environmental decision making [16]. MDDSSs are developed to support assessments of decisions pertaining to urban environmental management, so they should be able to detect a wide variety of time-space conditions [17]. Strategies should be selected based on their compatibility with macro zone characteristics, requirements, and disasters. The number and type of the selected strategies were modeled based on their suitability, abilities, and compatibility with their corresponding macro zones and the defined dominant conditions of TAQZs. For determining the causes of air pollution and selecting the best solutions to the problem, three specific approaches were defined:

1. Monitoring the current conditions using spatial layers.

2. The interpretation of time series geo maps for training neural networks as a memorial part of the system.

3. Simulating multi-dimensional urban spaces by ANN matrices and SCGLs models (Fig. 5).

SCGLs helped monitor the pollution locations, sampling the pollution patterns and the duration and frequency of pollution emission for each defined macro zone [18-19]. The final integrated strategies selected for each macro zone had to ensure that no irreversible hazardous pollution was to occur again under any possible conditions. MCDA techniques and ANNs increase the capabilities of MDDSS in making decisions about urban air quality since, according to analyses, not only do they account for geographical and temporal variables in the final decisions, but also include priority ratings and the selected criteria based on expert opinions [20-21].

\section{Monitoring the Forecasting Model by SCGLs}

In order to identify the formation and development process of pollution patterns, SCGLs and ANN outputs in each of the TAQZs compared the variations in pollution levels in different time-series and zones. Therefore, model verification in this study was conducted by simulating all the data collected from air quality control stations in the last year on SCGLs and comparing the results obtained with the outputs of the forecasting model, which confirmed the

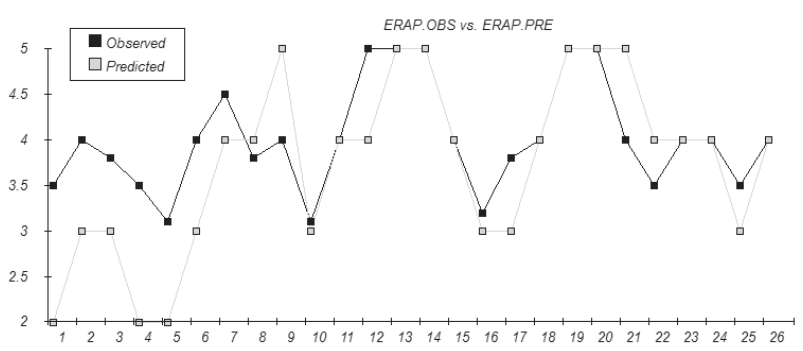

Fig. 6. Model verification by comparing actual values with the outputs of the predictive model.

conformity between the results of the forecasting model and environmental reality in $78 \%$ of the cases in terms of the formation and development of pollution. Final outputs of ANN models indicate that, based on implementing the selected strategies in the defined scenarios, air quality remains completely and sustainably healthy across all TAQZs in Tehran in the optimistic scenario, while air pollution level is reduced by more than $86 \%$ in fall and winter in the scenario defined for ordinary conditions. On the other hand, the pessimistic scenario suggests a mere $67 \%$ reduction in air pollution levels in winter despite implementing all the selected strategies while simulation results obtained using the SCGL indicate that the major remaining pollution is seen only in central parts of the city.

The outputs of predictive model determined the distribution of pollution levels across urban zones at $23 \%$ underestimate values by comparing the actual measured values. The final verification diagram shows that the expected pollution level patterns in each zone follow similar trends in both observed and predicted values (Fig. 6).

\section{Interpretation the STUDSS Results for Tehran Air Quality}

Compared to similar procedures, the present article conducted an integrated study on three indicators of public satisfaction, economic development, and sustainable clean air maintenance in all the studied TAQZs for the first time. All these three goals could be achieved using planning tools such as STUDSS [22]. Assessing the effect of pollutants and pollution patterns in different seasons and times and in local and regional zones requires longterm monitoring [23-24]. The dominant behavioral and physical patterns of pollution can be identified at different times and locations, so that their results can help the implementation and execution of the modeling stages associated with the evaluation and prediction of pollution (based on spatial thematic layers, time series data, and uncertainty scenarios) [25-26]. The air pollution level forecasting software not only simulates the pollution mitigation coefficients in each of the selected scenarios and zones, but also models other factors affecting the increase or decrease in air pollution based on the function and rules defined in MCDA and ANN, thereby providing urban managers with final results as the SCGLs. 


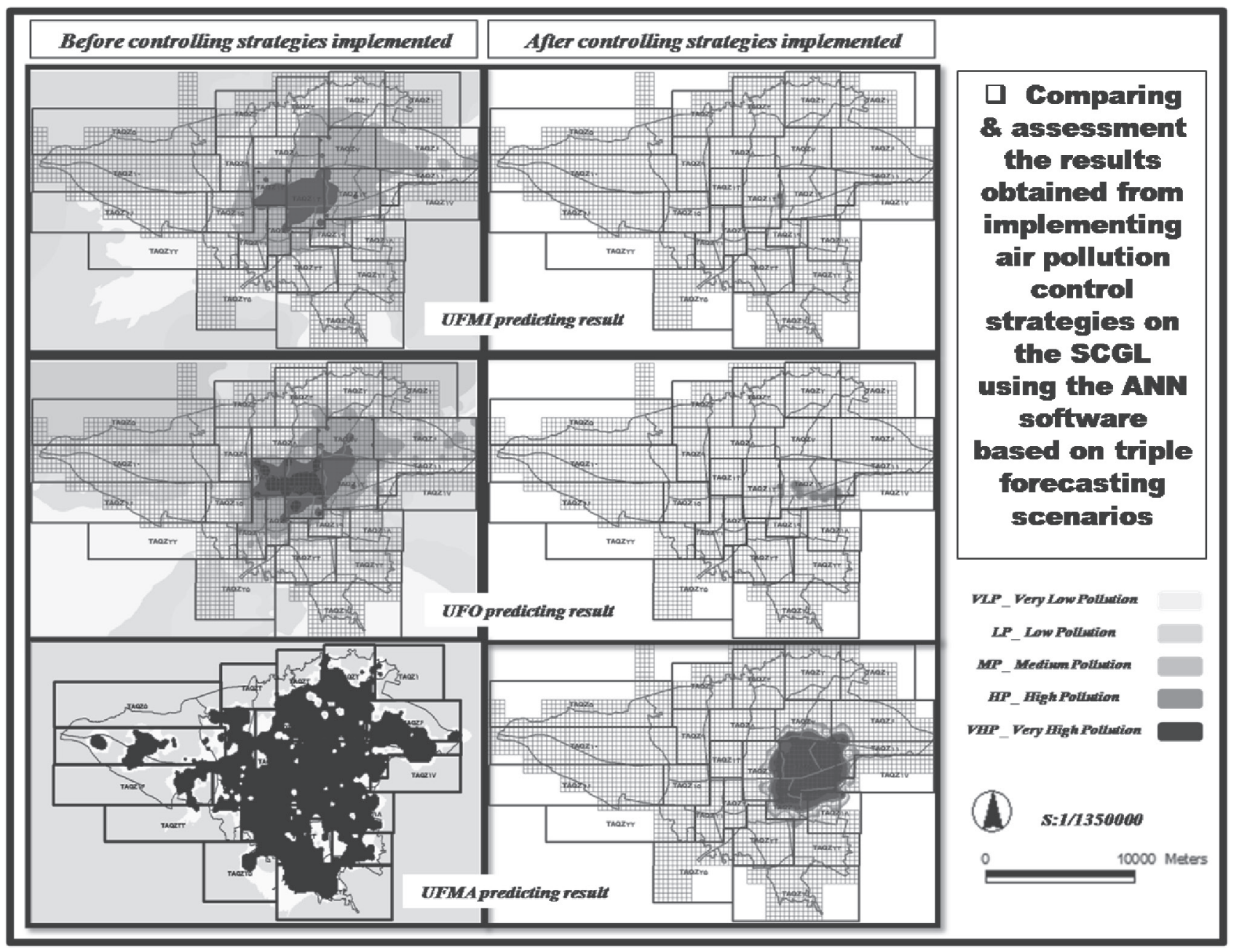

Fig. 7. The ANN results for predicting air pollution in each of the macro zones after implementing the control strategies defined by uncertainty scenarios and the SCGL overlaying models.

Uncertainty modeling based on the defined predicting scenarios could have a major role in robust decision making due to the complexities and the multidimensional aspects of urban air pollution. The defined tripartite scenarios help decision-makers in simulating the probable impact of the main spatio-temporal and stochastic variables on pollution dispersion in the specific macro zones. Comparing and illustrating the results obtained from implementing air pollution control strategies on the SCGL using the ANN software based on triple forecasting scenarios (including pessimistic, ordinary, and optimistic) suggest a perfect and stable reduction $(100 \%)$ in air pollution in all zones of Tehran in cases of implementing the selected scenarios in the UFMI (optimistic) scenario. Moreover, results of ANN models indicate that over $33 \%$ of pollution remain across the city zones (i.e., TAQZ12-TAQZ13-TAQZ18TAQZ19-TAQZ20-TAQZ27) in the fall and winter despite implementing air pollution control strategies in the UFMA (pessimistic) scenario. Furthermore, less than 14\% of air pollution remains in some zones (i.e. TAQZ12-TAQZ13TAQZ11) in fall and winter in the UFO (ordinary) scenario if the selected scenarios are implemented (Fig. 7).

\section{Conclusion}

The STUDSS model implemented a proactive interaction between spatio-temporal and uncertainty databases with visualization levels that assessed specific strategies for all the micro zones. Spatio-temporal analysis helped assess and predict the impact of pollution and identify the best pollution control strategies for the affected zones based on multidimensional decision-making models. Through the spatial simulation of the hazardous zones and the vulnerable spaces, the requirements for the selected strategies were determined at each specific TAQZ. The mitigation of air pollution accounted for by the executed strategies was calculated and simulated by MCDA-ANN matrices as well as SCGLs for each defined macro zone. The calculated scores and matrix outputs were ultimately visualized on spatio-temporal layers and utilized for uncertainty scenario modeling using the STUDSS method. Urban air pollution models simulate space contamination morphology evolution under various scenarios by assessing the most influential variables such as structures attributes, socioeconomic status, and 
the effects of complex local environment interactions. MDDSSs are able to effectively predict the time and place of the occurrence of increased pollution based on the recorded variables and time patterns, and can accurately guide decision-makers in assessing current and future air quality in various urban zones for further planning and decision making.

\begin{tabular}{|c|c|}
\hline DESCRIPTION & ABBREVIATION \\
\hline Multi-dimensional decision support systems & MDDSS \\
\hline Artificial neural network & ANN \\
\hline Multi-criteria decision analysis & MCDA \\
\hline Spatio-temporal and uncertainty decision support system & STUDSS \\
\hline Total suspended particulates & TSPs \\
\hline Spatial cellular grid layers & SCGLs \\
\hline Tehran air quality zones & TAQZs \\
\hline Point sources pollution control programs & PSP \\
\hline Line sources pollution control programs & LSP \\
\hline Laws and rules & LR \\
\hline Area sources pollution prevention programs & ASP \\
\hline Land use renovating and transportation system revised for access to sites of attraction programs & LUTA \\
\hline Demographic data for preparing and developing air-friendly programs & DD \\
\hline Urban spaces and structures for air-friendly planning and design & USS \\
\hline Behavioral pattern policies & BP \\
\hline Urban transportation and movement pattern planning & UTMP \\
\hline Urban corridor and useful topographical spaces planning and design & UCT \\
\hline Urban green areas and open spaces planning and design & UGOS \\
\hline Technology and virtual electronic services development and planning & TV \\
\hline $\begin{array}{l}\text { Urban designs and comprehensive plans revised by implementing clean air- } \\
\text { friendly policies in urban areas }\end{array}$ & UDCP \\
\hline Economical and technological policy development & ET \\
\hline Expected rates of air pollution & ERAP \\
\hline Uncertainty functions by ordinary scoring & UFO \\
\hline Uncertainty functions by maximum scoring for the worst possible conditions & UFMA \\
\hline Uncertainty functions by minimum scoring for the most optimistic forecast and positive conditions & UFMI \\
\hline Expected rates of air pollution mitigation & ERAPM \\
\hline Point source pollution density factors & PSPD \\
\hline Linear source pollution density factors & LSPD \\
\hline Land use impact classification rates & LAIR \\
\hline K values for ( Pspd + Lspd + LAir) constant factors & Kplla. \\
\hline The variable values measured through modeling the Hidr + Aidr + Asdr + Pdr + Eii factors & Vhaape inconstant \\
\hline Population density rates & PDR \\
\hline Heat islands density classification rates & HIDR \\
\hline Accepted clean air urban spaces density rates & ASDR \\
\hline Accepted air-friendly urban Infrastructures classification density rates & AIDR \\
\hline Environmental impact index simulations & EII \\
\hline
\end{tabular}


Compared to similar studies, the STUDSS model for the first time supports environment managers with analysis of previous conditions, evaluation of the results obtained from their own controlling strategies, and prediction of future conditions based on identified uncertainty scenarios. It also helps meet public satisfaction and economic development in different urban zones and enables the managers to plan using precaution of the results obtained from their own decisions on sustainable clean air maintenance. The present study evaluated and modeled "uncertainty" as a "dimension" along with other dimensions forming the environment, such as "spatiotemporal" factors for the first time. Moreover, the defined scenarios guarantee the reconstruction of all possible future conditions. The STUDSS prevents the loss of financial resources, causes economic development, and provides decision-making managers with a tool for investigating how to maintain clean air as the most significant challenge in an urban environment.

\section{Acknowledgements}

This research received the financial support from Tehran Urban Planning and Research Center. The spatial data and other data used in the present study were collected from a variety of sources, including Tehran GIS Center, Department of the Environment, the National Cartography Organization, the Statistical Center of Iran, Tehran Municipality Information and Communications Technology Organization and Tehran Municipality.

\section{References}

1. Tehran Municipality, Atlas of Tehran Metropolis, ICT organization, Tehran, IRI, 2012.

2. COFALA J., AMANN M., ASMAN W., BERTOK I., HEYES C., HOEGLUND I.L., KLIMONT Z., SCHOEPP W., WAGNER F. Integrated assessment of air pollution and greenhouse gases mitigation in Europe. Archives of Environmental Protection. 36 (1), 29, 2010.

3. WAISIU L., HART M. A. Quantifying urban heat island intensity in Hong Kong SAR, China, Environmental Monitoring and Assessment, 185, 4383, 2012.

4. CHENG B., LI S., WANG M., LI Y., Investigation of Combined Pollution between Malathion and a Variety of Pollutants Based on the Fractional Factorial Design, Polish Journal of Environmental Studies, 24 (5), 1939, 2015.

5. ZHU Y.G. Environmental impacts of rapid urbanization in China: a showcase of recent research developments, Environment Science and Pollution Research, 19, 1351, 2012.

6. KOBUS D., KOSTRZEWA J. The use of spatial data processing tools for air quality assessments - practical examples, Air Quality Monitoring Department, Institute of Environmental Protection - National Research Institute (IOS-PIB), Information Systems in Management: 4, 251, 2015.

7. CAI Y., ZHANG H., PAN W. Detecting Urban Growth Patterns and Wetland Conversion Processes in a Natural Wetlands Distribution Area, Polish Journal of Environmental
Studies, 24 (5), 1919, 2015.

8. JANK R., KELLEROV D., SCHIEBER B. Spatial and Temporal Variations in $\mathrm{O}_{3}$ Concentrations in Western Carpathian Rural Mountain Environments, Polish Journal of Environmental Studies, 24 (5), 2003, 2015.

9. KANEVSKI M. Advanced Mapping of Environmental Data, Geo statistics, Machine Learningand Bayesian Maximum Entropy, John Wiley \& Sons, Inc., River Street London W1T 5DX Hoboken, UK, 2011.

10. SYP A., FABER A., BORZĘCKA-WALKER M., OSUCH D. Assessment of Greenhouse Gas Emissions in Winter Wheat Farms Using Data Envelopment Analysis Approach, Polish Journal of Environmental Studies, 24 (5), $2197,2015$.

11. YOUNSI Z., HAMDADOU D., BOUAMRANE K. Integration of GIS and Artificial Neural Networks Faculty of Sciences, University of Oran, Algeria, Published by The International Federation of Surveyors (FIG), DK-1780 Copenhagen Denmark, 2010.

12. WALLENIUS J.D., DYER J.S., FISHBURN P.C., STEUER R.E., ZIONTS S., DEB,K., Multiple criteria decision making, multi attribute utility theory: Recent accomplishments and what lies ahead. Management Science, 54 (7), 1336, 2008.

13. NEJADKOORK F., NICHOLSON K. Integrating passive sampling and interpolation techniques to assess the spatiotemporal variability of urban pollutants using limited data sets, Environmental Engineering and Management Journal, 11 (9), 1649, 2012.

14. FISCHER M.M., GETIS A. Handbook of Applied Spatial Analysis - Software Tools, Methods and Applications Springer-Verlag Berlin Heidelberg / 35, 2011.

15. HOLNICKI P., NAHORSKI Z., TAINIO M. Uncertainty in air quality forecasts caused by emission uncertainty. Proceedings of HARMO 13th Conference on Harmonization within Atmospheric Dispersion Modeling, 119, ISBN 2-8681-5062-4, Paris, France, June 1-4, 2010.

16. GSCHWIND B., LEFEVRE M., BLANC I., RANCHIN T, WYRWA A., DREBSZOK K., COFALA J., FUSS S. Including the temporal change in $\mathrm{PM}_{2.5}$ concentration in the assessment of human health impact: Illustration with renewable energy scenarios to 2050, Environmental Impact Assessment Review, 2014.

17. ELBIR T., MANGIR N., KARA M., SIMSIR S., EREN T., OZDEMIR S. Development of a GIS-based decision support system for urban air quality management in the city of Istanbul. Atmospheric Environment, 44 (4), 441, 2010.

18. LU P., MEI K., ZHANG Y., LIAO LINGLING, LONG B., DAHLGREN RANDY A., ZHANG M. Spatial and temporal variations of nitrogen pollution in Wen-Rui Tang River watershed, Zhejiang, China, Environmental Monitoring and Assessment, 180, 501, 2011.

19. FILIP A., DRAG P. The creation of "questions bank" and introduction of two examination session, Information Systems in Management, 4, 241, 2015.

20. NYERGES T., RODERICK M., PRAGER S., BENNETT D., LAM N. Foundations of sustainability information representation theory: spatial-temporal dynamics of sustainable systems, International Journal of Geographical Information Science, 28 (5), 1165, 2014.

21. PECKHAM S., GRELL G., MCKEEN S., FAST J., GUSTAFSON W., GHAN S. Characterization of urban air quality using GIS as a management system. Environmental pollution, 122 (1), 15, 2010.

22. GETTINGER J., KIESLING E., STUMMER C., VETSCHERA R. A comparison of representations for discrete multi-criteria decision problems, Decision Support Systems, 54, 976, 2013. 
23. JIMÉNEZ E., TAPIADOR F.J., SÁEZ-MARTÍNEZ F. Atmospheric pollutants in a changing environment, Environment Science and Pollution Research, 22, 4789, 2015.

24. WOTAWA F., RODRIGUEZ-RODA I., COMAS J. Environmental decision support systems based on models and model-based reasoning, Environmental Engineering and Management Journal, 9 (2), 189, 2010.
25. LIN B.B., MOREFIELD P.E. The Vulnerability Cube: A Multi-Dimensional Framework for Assessing Relative Vulnerability, Environmental Management, 48, 631, 2011.

26. MATKANA., SHAKIBAA.R., PURALI S.H., BAHARLOO

I. Determination of Spatial Variation of CO and PM10 Air Pollutants, Using GIS Techniques (Case study : Tehran, Iran), International Geomatic conference, Tehran, Iran, 2011. 